\section{RHEOSTATIC MACHINE}

$\mathrm{T}$ is known that Franklin made use of a series of 1 Leyden jars or fulminating plates, arranged in the form of a cascade, to obtain strong discharges of static electricity; that, on the other hand, Volta, Ritter, Cruikshank, \&c., were able to charge condensers by means of the pile, and that these results gave rise to researches, conducted both by calculation and experiment, on the part of a great number of physicists.

I have been led to study, in my turn, the static effects of voltaic electricity, by means of a secondary battery of 800 couples which I at present possess; and I have devised an apparatus which shows the intensity that these effects may acquire.

After having proved how easy it is with this battery to charge rapidly an insulating plate condenser, sufficiently thin, of glass, mica, guttapercha, \&c., I combined a certain number of condensers, formed by preference of mica covered with tinfoil, and arranged them as couples of the secondary battery itself, so as to be easily charged in quantity, and dischaiged in tension.
All the pieces of the apparatus must be carefully insulated. The commutator is formed of a long cylinder of hard caoutchouc, provided with longitudinal metallic bands, intended to unite the condensers at the surface ; and traversed at the same time by copper wires, bent at their extremities, for the purpose of uniting the condensers in tension. Small plates or metallic wires formed into springs are placed in connection with the two arma. tures of each condenser and fixed on an ebonite plate on each side of the cylinder, to which a rotatory movement can be given.

If we put the two sides of the apparatus into communication with the secondary battery of 800 couples, even several days after having charged it with two Bunsen elements, and if we set the commutator in rotation, we obtain, between the branches of the excitator, on which the armatures of the extreme condensers abut, a series of sparks entirely similar to those given by electric machines provided with condensers. By employing an apparatus of only thirty condensers, each of three square decimetres of surface, I have obtained sparks four centimetres in length.

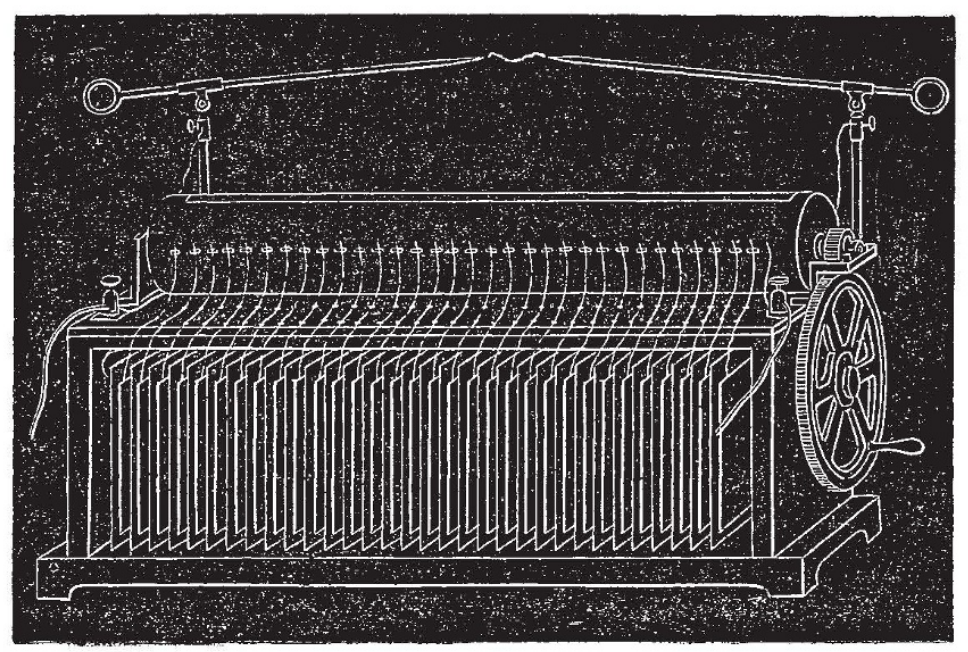

The tension of a secondary battery of 800 couples is not necessary to produce marked effects with this apparatus. By putting in action only 200 couples, we have sparks of eight millimetres, and we may, without doubt, by diminishing still more the thickness of the insulating plates and inultiplying the number of condensers, obtain effects with a source of electricity of less tension.

It is to be remarked that the discharges of static electricity, furnished by this apparatus, are not in directions alternately positive and negative, but always in the same direction, and that the loss of force resulting from the transformation must be less than in the induction apparatus; for, as the voltaic circuit is not closed a single instant on itself, there is no conversion of a part of the current into heat.

We may maintain the apparatus a long time in rotation and produce a considerable number of discharges without the secondary battery appearing sensibly weakened. This is because each discharge employs only a very small quantity of electricity, and because, as above stated, the circuit of the battery is not closed by a conducting body. The electricity of the source simply spreads over the polar surfaces presented by all the condensers, in proportion as they are discharged. This emission constantly repeated must nevertheless end by discharging a certain quantity of electricity; and when the instrument is charged by a secondary battery, we must ultimately exhaust, under the form of static effects, the limited quantity of electricity which the current of the battery can furnish.
Thus then, by another method than that of induction, properly so-called, by means of a simple effect of static influence renewed without cessation, we effect the transformation of dynamic electricity, so that this apparatus may be designated by the name of "rheostatic machine."

GASTON Planté

\section{GEOGRAPHICAL NOTES}

THE Berlin Geographical Society celebrated in characteristic German fashion the fiftieth anniversary of its foundation last week. Berlin, as our readers know, is not the only German city possessing a geographical society; indeed it has two. In Hamburg and Bremen are two excellent societies of this class, while the Continent, generally, is ovcrum with them. Russia has about a dozen, Belgium has at least two, Brussels and Antwerp, Holland one if not more, France at least half a dozen, Italy two or three, and the Scandinavian countries their own share. We do not consicler it a disadvantage that in maritime countries there should be more than one geographical society, and we think it might be beneficial if even in our own country associations corresponding to the French societies of commercial geography were established in our chief ports, Liverpool, Glasgow, Bristol, Leith, Dunclee. These might be branches of or affiliated to the London society, and might catch much that never reaches the latter. They might, moreover, do considerable service in encouraging the 
merchant service to obtain and bring home information that would be useful to science, and might, by means of lectures and otherwise, foster a scientific spirit among our commercial population. Much good is done in this way, we believe, by the societies of Marseilles, Bordeaux, and Lyons. Two new geographical societies have, we learn, been established in France, at Metz and Montpellier. The French are evidently doing their best to remove the reproach so frequently cast at them, of being more ignorant of geography than even the English.

THAT the Continental societies go in for earnest work is evident from the weighty journals published by most of them. The Mittheilungen of the Hamburg Society for 1876-77, for example, is a thick volume of 400 pages, containing a number of papers of considerable scientific value. Besides several papers on Central and South America, there is a long series of letters by Dr. Pfund, filling nearly half the volume, written during his travels in Kordofan and Darfur, along with Colonel Prout, of the Egyptian staff. Other African papers are by Dr. Paul Ascherson on his travels in the Lybian desert in I876, and one of much value by Herr Fischer, on the present condition of the Galla Country. In the Deutsche Geographische Blätter, the organ of the Bremen Society, Dr. Oskar Lenz discusses at length the trade conditions in Equatorial West Africa, with special reference to Stanley's discoveries; Dr. Lenz does not believe that the Ogovai is connected with the Congo. Mr. W. H. Dall is contributing to this journal a series of papers on his own and other recent researches in the Aleutian Islands, while Dr. A. Ziegler has an interesting paper on Regiomontanus and Martin Behaim. Turning to Italy the energetic Roman Society has begun the publication (apart from their always interesting Bolletino) of Memorie, containing at length the most important papers read at the Society's meetings. The first part contains a lecture by the president, Signor Cristifero Negri, on scientific geography, which shows what has more than once been said, that geography is really the meeting-place of all the sciences. Then there is a paper on the geographical distribution of camels, by Prof. Luigi Lombardini, and a well-arranged series of instructions to explorers by various specialists, edited by Signor A. Issel. Nor must we forget the American Society, with its seat at New York, and which is the medium for a good deal of valuable information that might not otherwise reach the light of day. Chief-Justice Daly's presidential address always contains an admirable and exhaustive summary of the year's work ; and this year it is quite as full and interesting as usual, nothing in the domain of geography of any importance remaining untouched, special prominence being of course given to the various surveys of the United States. Thus it will be seen, that under the name of geography, much varied and really valuable work is being done, and that dilletanteism has really but a small place in it, at least abroad.

AN expedition, comprising twenty-five miners and others, has started for New Guinea. This news is telegraphed from Sydney, and we earnestly hope that the expedition is under proper direction, both for the sake of the natives, who have so far been friendly to white men, and for the sake of further scientific discovery.

\section{THE TRANSIT OF MERCURY}

$T$ HE weather on Monday was so unfavourable that the observations of this interesting phenomenon were mostly unfortunate in England. In France some valuable observations seem to have been made. Our Paris Correspondent writes that the observations taken by $M$. Janssen at Meudon Observatory were wonderfully successful considering the state of the atmosphere. He was able to make use of spectrum analysis in order to deter- mine the composition of Mercury's atmosphere. He was able to see Mercury before it had begun to make its first entrance on the disc. This observation is a confirmation of the phenomena observed in 1874 at Yokohama on the occasion of the Transit of Venus. Two photographs are excellent, and will lead to a determination of the diameter of the planet. At the Paris Observatory the transit was also seen.

When Capt. Mouchez saw Mercury the disc had been indented to the extent of $2^{\prime \prime}$ of degree, about ${ }_{6}^{\prime}$ th diameter of Mercury. When it was seen by the brothers Henry it was half on the disc. The difference of time is about $10^{\prime}$ later at the National Observatory. The brothers Henry also saw the interior contact at about $3 \mathrm{~h} .23 \mathrm{~m}$. and some seconds. The exact time cannot be given yet. The cortact was decidedly bad owing to the clouds.

At Algiers and Bordeaux the observations were bad. At Ogden, Utah, United States, the delegates sent by the French Government, M. André, of Lyons, and M. Angot, of Paris, obtained seventy-eight photographs of the transit. Satisfactory observations and photographs of the transit were taken at the Government Observatories at Washington and West Point, U.S.

Mr. J. J. Cole writes to the Times from Mayland, Sutton, Surrey, that the sun was clear from 3.5 to 3.25 , and the whole ingress was steadily observed with a refractor of 6 inch aperture and three others smaller. The Greenwich mean times of external and internal contact were taken, and were confirmed by $\mathrm{Mr}$. Bawtree near with unexpectedly small differences.

At Aberdeen the transit was observed by Lord Lindsay, Mr. Ranyard, Dr. Copeland, Mr. Carpenter; and Herr Lohse, and photographed by Mr. Davis. A thin cloud covered the sun at the time of first contact. No ring of of light was seen round the part of the planet off the sun's disc. External contact was observed spectroscopically by Lord Lindsay, who detected the approach of the planet by the eclipse of the $C$ line thirteen seconds before its limb encroached upon the continuous spectrum of the photosphere. Mr. Ranyard observed the continuous spectrum below $C$ line, but saw no trace of the planet until it was on the sun's disc. No change in the solar spectrum was observed at the limb of the planet. Dr. Copeland, Mr. Carpenter, and Herr Lohse obtained both contacts and measures of diameter.

Mr. C. G. Talmage writes as follows to the Times from Mr. Barclay's Observatory, Leyton, Essex :-

"Owing to the prevalence of clouds the times of external and internal contact at ingress were not observed here. The first view I obtained was at 3.43, when Mercury had advanced some considerable distance on the sun's disc. The duration of clear sky was then so short that there was not sufficient time to obtain micrometrical measures of distance from the sun's limb. For about eight or ten seconds the sky was absolutely clear, arrd then I noticed that Mercury was surrounded by a bright ring, darkening off to the periphery, which was exceedingly well defined. The distance between the limb of Mercury and periphery of ring was about two-thirds of the planet"s diameter. I used the full aperture of ten inches, with a diagonal power of eighty."

\section{DE CAILLETET'S APPARATUS}

WE have already (vol. xvii. p. 265) spoken at length of M. Cailletet's method of liquefying the last of the gases, and at the same time we referred to the fact that students of science in France had not been forgotten by the accomplished experimenter. We described briefly a portion of an apparatus for use in laboratories for this experiment, and are now able to give an illustration of the complete laboratory apparatus as manufactured by Ducretet and Co., of Paris. The figure shows the apparatus one-eighth the size of reality. 